\title{
GESTÃO ESCOLAR: A IMPORTÂNCIA DA GESTÃO DEMOCRÁTICA E PARTICIPATIVA NAS ESCOLAS PÚBLICAS BRASILEIRAS
}

\section{ARTIGO ORIGINAL}

NASCIMENTO, Francimária Santana de Sousa ${ }^{1}$

NASCIMENTO, Francimária Santana de Sousa. Gestão Escolar: A importância da gestão democrática e participativa nas escolas públicas brasileiras. Revista Científica Multidisciplinar Núcleo do Conhecimento. Ano 05, Ed. 09, Vol. 07, pp. 7583. Setembro de 2020. ISSN: 2448-0959, Link de acesso: https://www.nucleodoconhecimento.com.br/educacao/escolas-publicas

\section{RESUMO}

Fazer com que a comunidade escolar participe do processo de gestão nas escolas públicas brasileiras tem sido um anseio e também um dos grandes desafios da gestão escolar nos dias atuais, porque é somente através da participação ativa de todas as pessoas que fazem parte do processo educacional é que pode se dizer que de fato existe uma gestão escolar democrática e participativa. Este artigo tem como objetivo principal mostrar de uma forma dialógica e analítica o que é gestão, como ela acontece e qual é a importância de se ter uma gestão democrática e participativa na escola pública brasileira e como ela pode colaborar na construção de uma educação de qualidade e que venha contribuir para a transformação social da comunidade como um todo, fazendo com que todos conheçam e saibam qual é o seu real papel e a sua importância dentro deste processo. Será discutido a respeito do papel do gestor escolar e da importância do planejamento no processo de gestão democrática participativa. Para isso foi feito uma pesquisa bibliográfica na qual buscou-se a

\footnotetext{
${ }^{1}$ Mestranda em Ciências da Educação pela Zoe University, Pós-graduada em Gestão Escolar pela Universidade Federal do Tocantins (UFT), licenciada em Pedagogia pela Universidade Estadual do Tocantins (UNITINS), licenciada em Normal Superior pela Universidade Estadual do Tocantins (UNITINS).
} 
contribuição de autores como Dourado (2001); Libâneo (2018); Lück (2011) e a Lei de Diretrizes e Bases da Educação Nacional (LDB) lei no 9394/96.

Palavras-Chave: Gestão democrática e participativa, comunidade escolar, gestor, planejamento.

\section{INTRODUÇÃO}

Ao longo da história da escola, pode-se dizer que a comunidade esteve afastada e se quer teve interesse em ter uma participação efetiva na gestão escolar e educacional. Isso era visto como uma responsabilidade apenas dos gestores escolares em que os mesmos tinham que se preocupar com a cultura organizacional, estabelecer metas e buscar resultados, se tornando o centro do processo educacional da escola, fazendo com que a gestão democrática e participativa não acontecesse, ou seja, ela não existia no contexto escolar, todas as decisões eram tomadas pelo gestor que antes recebia o nome de diretor. No entanto com a Constituição Federal de 1988 e com a lei no 9.394/96 em que estabelecem o princípio de gestão democrática nas escolas públicas do país, a gestão democrática e participativa passa a ter um grande enfoque e também uma grande discussão de como fazer com que todos os atores sociais que fazem parte da comunidade escolar participem da gestão nas escola, mesmo se passado muito tempo em que se discute e procura-se implantar a gestão democrática e participativa nas escolas, ainda existe uma certa dificuldade na participação de todos os envolvidos nesse processo.

Para que realmente seja feito a implementação da gestão democrática e participativa nas escolas públicas brasileira, é preciso que todos os envolvidos, tanto a comunidade escolar quanto a comunidade local e a sociedade em geral, conheçam e entendam a importância da gestão democrática participativa como ela acontece e qual é o seu papel e a importância que tem a sua participação nesse processo.

Com o objetivo de dialogar e analisar como acontece e se desenvolve e qual a importância de se ter uma gestão democrática e participativa dentro da escola pública brasileira é que esse trabalho foi desenvolvido, baseado em uma pesquisa 
bibliográfica em que a mesma busca através de um aporte teórico de autores como Dourado (2001), Libâneo (2008) Lück (2011) e a Lei de Diretrizes e Bases da Educação Nacional (LDB) lei no 9394/96, conceituar o que é gestão democrática? Qual a importância de uma gestão participativa? Qual a importância do gestor e do planejamento na gestão escolar? Iniciaremos a discussão, conceituando a gestão e a sua importância no processo de construção de uma gestão democrática e participativa nas escolas públicas brasileiras.

\section{O QUE É GESTÃO DEMOCRÁTICA? E QUAL A IMPORTÂNCIA DE UMA GESTÃO PARTICIPATIVA NAS ESCOLAS PÚBLICAS?}

Faz-se necessário conceituar gestão, que é entendida como uma atividade pela qual são mobilizados meios e procedimentos para atingir os objetivos da organização, envolvendo, basicamente os aspectos gerenciais e técnico-administrativos, ou seja, gestão pressupõe participar envolver no caso da escola pessoas nos processos educacionais visando $o$ atendimento de uma demanda social.

Gestão é um processo de mobilização da competência e da energia de pessoas coletivamente organizadas para que, por sua participação ativa e competente, promovam a realização, o mais plenamente possível, dos objetivos de sua unidade de trabalho, no caso os objetivos educacionais. O entendimento do conceito de gestão, portanto, por assentar-se sobre a maximização dos processos sociais como força e ímpeto para a promoção de mudanças, já pressupõe, em si, a ideia de participação, isto é, do trabalho associado e cooperativo de pessoas na análise de situações, na tomada de decisão sobre seu encaminhamento e na ação sobre elas, em conjunto, a partir de objetivos organizacionais entendidos e abraçados por todos. (LÜCK, 2011, p. 21).

Com isto entende-se que a gestão é um processo muito importante, porque mobiliza todos os que estão ou que fazem parte de um contexto, seja ele social ou educacional e para que aconteça essa mobilização é preciso que essa gestão esteja inserida numa perspectiva democrática na qual tem sido um dos elementos mais presentes nos debates dos profissionais da educação, porque é somente com a participação de todos os envolvidos no processo educacional, contribuindo e colaborando de forma ativa e envolvidos na tomada das decisões, que dizem respeito a escola e a educação 
é que pode-se melhorar a educação como um todo possibilitando a construção de um ensino e de uma educação de qualidade nas escolas públicas do nosso pais, mas para que isso aconteça é preciso que haja uma participação de todos, tanto da equipe gestora quanto da comunidade escolar e local nos processos decisórios educativos da escola e isso só será possível através de uma gestão escolar democrática e participativa que assegure a participação de todos os atores sociais envolvidos no processo educacional.

Essa participação atualmente acontece nas escolas públicas, através de Conselhos Escolares, Conselhos de Classe, Associações de Pais e Mestres, Grêmio Estudantil e existem também os Conselhos Nacionais, Estaduais e Municipais de Educação nos quais são estão tipificados na LDB.

Estes órgãos constituem-se como um espaço em que há a participação de forma colegiada e coletiva nos processos de normatização do processo educacional e deliberam sobre decisões que podem impactar de forma positiva ou negativa os sistemas educacionais de ensino, espaço esses em que todos de forma organizada e colegiada podem participar, opinar, , deliberar, construir propostas e decidir a respeito do que é preciso ser feito de forma legal para termos uma educação e um ensino de qualidade.

A Lei de Diretrizes e Bases da Educação Nacional Brasileira (LDB, Lei 9.394/96, já estabelece e determina a respeito da gestão democrática e sobre a participação de todos os envolvidos no processo educacional nos artigos $3^{\circ}$ e $14^{\circ}$.

Art. $3^{\circ}$. O ensino será ministrado com base nos seguintes princípios: (...) VII - gestão democrática do ensino público, na forma desta Lei e da legislação dos sistemas de ensino; (...). Art. $14^{\circ}$. Os sistemas de ensino definirão as normas da gestão democrática do ensino público na educação básica, de acordo com as suas peculiaridades e conforme os seguintes princípios: I - participação dos profissionais da educação na elaboração do projeto pedagógico da escola; II - participação das comunidades escolar e local em conselhos escolares e equivalentes. (CARNEIRO, 2012, p. 49, 171) 
Isso quer dizer que quanto maior for à participação e o envolvimento dos profissionais da educação e de toda a comunidade escolar no processo de tomada de decisão melhor será para a educação e maior será a sua produtividade e consequentemente contribuirá para a construção de uma sociedade mais justa, digna e igualitária para todos.

Desta forma, podemos dizer que a participação proporciona mudanças significativas na vida das pessoas, na medida em que elas passam a se interessar e sentir-se responsáveis por tudo que representa o interesse comum. Participar ativamente no processo de escolha e nas decisões escolares faz com que os envolvidos tenham mais responsabilidade e aprendam a desenvolver a noção de coletividade e promovam mudanças que irá possibilitar a melhoria não só do processo educacional das escolas, mas da comunidade em geral.

A gestão escolar, numa perspectiva democrática, tem características e exigências próprias. Para efetivá-la, devemos observar procedimentos que promovam o envolvimento, o comprometimento e a participação das pessoas. Para isto, torna-se necessário promover atividades e exercer funções que promovam a presença e o fortalecimento da atuação das pessoas no interior das escolas. No entanto, o modo democrático de gestão envolve o exercício do poder, incluindo os processos de planejamento, a tomada de decisões e a avaliação dos resultados alcançados, etc... Trata-se, portanto, de fortalecer procedimentos de participação das comunidades escolar e local no governo da escola, descentralizando os processos de decisão e dividindo responsabilidades. (DOURADO, 2011, p. 15)

Numa gestão democrática é entendido que para ela acontecer é preciso que haja a participação de forma coletiva de todos os envolvidos no processo educacional, é necessário também que possua gestores capacitados e compromissados com o processo de ensino e aprendizagem, que tenha capacidade para planejar e delegar funções e tarefas, que saiba e entendam de planejamento para que possa fazer com que todos os envolvidos participem de forma ativa e com e isso ajude a favorecer também o desenvolvimento de uma cultura na qual toda a comunidade reconheça $\mathrm{e}$ entenda a importância do patrimônio das instituições educativas ou seja, a escola. 
Nesse contexto, pode-se dizer que a gestão democrática participativa na escola requer a participação da comunidade nas ações desenvolvidas na escola. Sabemos que nem sempre é uma tarefa fácil, competindo ao gestor e a equipe gestora pensar e desenvolver estratégias para motivar as pessoas a se envolverem e participarem da vida da escola e isso tem dificultado e muito o envolvimento dessas pessoas, porque demanda tempo e disponibilidade, coisa que muitos não têm, por isso é necessário que haja um bom planejamento por parte da equipe gestora para que possa com isso assegurar a presença e a participação de todos os envolvidos nesse processo. E é sobre planejamento que será tratado no próximo tópico, da sua importância para que seja assegurado a participação de todos os atores sociais que fazem parte do processo de gestão escolar democrática e participativa nas escolas públicas do nosso país.

\section{O PLANEJAMENTO NO PROCESSO DE GESTÃO DEMOCRATICA PARTICIPATIVA}

O planejamento faz parte das atividades gestoras de todas as unidades escolares. Podemos afirmar que ele é parte intrínseca do fazer pedagógico, porém é necessária a participação real de todos os atores sociais e para que isso aconteça o gestor tem um papel fundamental para que essa participação aconteça de fato.

Para se ter uma boa participação de toda a comunidade escolar dentro de uma gestão democrática é preciso que a equipe gestora saiba planejar bem suas ações tendo em vista que $o$ ato de planejar deve ser uma atividade constante no contexto educacional e que um gestor para construir uma administração democrática deve ter um planejamento coletivo e participativo porque uma escola democrática pressupõe uma forma de gestão também democrática, onde terá que ter a preocupação com a participação de todos os membros da comunidade escolar (alunos, pais, professores, coordenadores, gestores...) um gestor democrático deve estimular a integração dentro da escola para que haja união entre os funcionários e alunos. Deve também estabelecer um elo de harmonia, participação e parceria com a comunidade local, deve ter capacidade e competência para liderar a equipe e a comunidade escolar da 
qual ele gerencia e também incentive as pessoas a terem também a capacidade de liderar.

Liderança é a capacidade de influenciar, motivar, integrar e organizar pessoas e grupos a trabalharem em execução de objetivos. Em uma gestão participativa, não basta que haja na equipe certas pessoas que apenas administrem a realização das metas, objetivos recursos e meios já previstos. É preciso que se consiga da equipe o compartilhamento de intenções e valores, práticas, de modos que os interesses do grupo sejam canalizados para esses objetivos, e que várias pessoas possam assumir a liderança e desenvolver essas qualidades (LIBÂNEO, 2008, p. 89)

Sabe-se que isso não é uma tarefa fácil desenvolver este tipo de liderança, mas é possível fazer com que os membros da comunidade escolar participem da conjuntura relevante de uma escola. Desde que haja um planejamento para conscientizá-los, usando não só os comunicados formais como tem acontecido em algumas unidades de ensino, mas também através de diálogos informais, mostrando as pessoas que estão envolvidas nesse processo a importância da sua participação. Porque acreditase que a conscientização dos pais e a sua participação e interação com assuntos referente à educação do seu filho é de grande valia para o crescimento intelectual de uma criança, podemos afirmar que o diálogo é uma das formas mais correta de formar um cidadão democrático e reflexivo para sobreviver neste mundo desigual cheio de preconceito e individualismo.

Para que aconteça nas escolas um planejamento democrático, às decisões devem ser tomadas de comum acordo entre os diferentes membros da comunidade escolar, tendo sempre o cuidado de respeitar a heterogeneidade e a individualidade de cada um. A escola atual se depara com uma realidade diversificada com novos desafios educacionais, portanto devem-se estabelecer condições mais adequadas para atender as diversidades culturais e econômicas de cada da comunidade local.

Para transformar essa tradicional sociedade pautada pela exclusão, onde na maioria das vezes só tem poder da fala os gestores (políticos), ou uma pequena camada da sociedade principalmente (classe média), é preciso que seja trabalhada a democracia como um todo levando-a toda a comunidade e começando na escola através da 
participação e da interação de todos, começando desde as crianças até o mais alto grau de participação.

Nas escolas públicas para se alcançar uma educação de qualidade o gestor juntamente com os demais funcionários e comunidade escolar deve compreender e respeitar as diversidades de cultura existente no Brasil. Mas para que isso venha acontecer deve-se renovar toda a estrutura educacional deixando para trás a forma autoritária do ensino tradicional, onde o diretor era o que ditava as regras, não só para os alunos como para toda a U. E.

As reuniões escolares têm como objetivo de tomar decisões das questões pedagógicas, administrativa, financeira e cultural. Uma reunião bem planejada e organizada é um passo fundamental no desenvolvimento democrático de uma escola. Uma instituição democrática é construída com vínculo de confiança entre os membros, pois os projetos a serem desenvolvidos devem ter a participação de todos sendo fundamental para a concretização do trabalho. Na instituição escola a integração é a meta principal para o desenvolvimento do aluno.

Para adotar medidas democráticas numa escola o Conselho de classe deve ser feito não só pelo os professores, mas também pelos os alunos, onde professores, aluno (líder de sala), gestor e coordenadores realizam reuniões todo o bimestre para solucionar os problemas envolvendo o aproveitamento dos educandos. O Conselho de Classe e o Grêmios estudantil são uns dos vários mecanismos que possibilitam a Gestão participativa democrática na Instituição Escolar e o gestor deve agir apenas como um mediador, respeitando as opiniões individuais, chegando a um consenso com a maioria, desde que essa maioria esteja de acordo com as normas educacionais, só através do coletivismo é que serão alcançados os resultados necessários para o desenvolvimento e aprovação dos projetos educacionais nos quais a escola precisa para que seja proporcionada e oferecida uma educação de qualidade. É através das reuniões escolares que se possibilita as mais diversas articulações feitas pela comunidade escola, e as informações, as decisões e os projetos são tomadas através das discussões feitas pelos responsáveis pela a melhoria da educação que são pais, professores, gestores enfim toda a comunidade escolar que juntos tomaram decisões 
mais adequadas para o bom planejamento e aprendizado no desempenho escolar dos alunos.

Para ser um gestor escolar com sucesso, um dos pontos mais relevante é ser um gestor capacitado com cursos adequado para o cargo e experiência, ser carismático, aberto para o diálogo, disciplinado e disciplinador, respeitado, participativo e sempre pronto para tomar iniciativas adequadas no momento certo na hora certa sem privilegiar A ou B. O gestor educacional não deve ser manipulado pelas manifestações políticas locais. A participação do poder público é essencial para a construção de uma gestão verdadeiramente democrática. Mas o que se sabe é que os políticos ainda interferem nas decisões educacionais principalmente nas escolas públicas dos interiores do Brasil. A escola pública depende de uma autonomia para melhor desenvolver seus projetos pedagógicos, e deixar de lado os desmandos políticos para só assim nossos alunos e comunidade local possam se sentir verdadeiros cidadãos livres e transparentes sem o menor receio de ser críticos e podendo com isso expressar suas opiniões.

\section{CONSIDERAÇÕES FINAIS}

Construir uma gestão democrática e participativa nas escolas públicas brasileiras é o anseio de todos que fazem parte da educação e lutam para que todos possam participar e ter acesso a uma educação e a um ensino de qualidade, isso não é uma tarefa fácil, mas é possível desde que haja políticas públicas que incentivem a participação de todos os envolvidos no processo educacional e considerando tudo que foi discutido e analisado numa perspectiva de gestão democrática e participativa percebemos que desenvolver esse tipo de gestão é um anseio de todos os profissionais da educação e principalmente da equipe gestora das escolas porque facilita no processo de tomada de decisão e ajuda a comunidade a entender o seu verdadeiro papel não só dentro do contexto educacional, mas na sociedade como um todo.

E para implementar e fazer com que seja uma realidade em cada escola o princípio constitucional de gestão democrática do ensino público nas escolas públicas do Brasil, 
é preciso também que haja gestores capazes de aplicar normas legais em situações mais diferenciadas. Para isso deve ter um conhecimento mais abrangente da Lei de Diretrizes e Base da Educação Nacional (LDB), dos Planos Nacional, Estadual e Municipal, ter uma formação acadêmica na área de gestão escolar, que saiba liderar e tenha autonomia didática e pedagógica para gerir o ensino e a educação escolar de forma a garantir a todos os educandos uma educação e um ensino de qualidade e com isso contribuindo para a formação de cidadãos críticos e reflexivos capazes de atuar e fazer parte da sociedade na qual ele se encontra inserido. Entendemos que isso faz parte de um processo e que está acontecendo aos poucos e que temos tudo para conseguir desenvolver essa gestão tão sonhada e idealizada por todos, que é a gestão escolar democrática e participativa.

\section{REFERÊNCIAS}

CARNEIRO, Moaci Alves. LDB fácil: leitura crítico-compreensiva, artigo a artigo; 20. Edição; Petrópolis RJ: Vozes, 2012. 581 p.

DOURADO, Progestão Módulo II: Como promover, articular e envolver a ação das pessoas no processo de gestão escolar. Brasília: CONSED, 2001126 p.

LIBÂNEO, José Carlos. Organização e gestão da escola: teoria e prática. 5. ed. rev. ampl. Goiânia: Livros MF, 2008.

LÜCK, Heloisa. A gestão participativa na escola. Petrópolis, RJ: 9 ed. Vozes, 2011 $125 \mathrm{p}$.

Enviado: Setembro, 2020.

Aprovado: Setembro, 2020. 